\title{
Assessment of changes in blood flow through the lungs and foramen ovale in the normal human fetus with gestational age: a prospective Doppler echocardiographic study
}

\author{
Martin St John Sutton, Alison Groves, Andrea MacNeill, Gurleen Sharland, \\ Lindsey Allan
}

\begin{abstract}
Objective-To measure lung blood flow and flow through the foramen ovale in the normal human fetus and to assess the changes in each with gestational age and the proportions of combined ventricular output that the respective flows represent.
\end{abstract}

Patients and design-38 normal fetuses (gestational age 18-37 weeks) were studied prospectively with Doppler echocardiography.

Methods-Echocardiographic images and Doppler velocity signals were obtained from the ascending aorta, main pulmonary artery, and ductus arteriosus from each fetus and digitised to obtain arterial diameters, heart rates, and velocity-time integrals. Blood flow in each artery was calculated as the product of heart rate, flow-velocity integral, and arterial cross sectional area. Blood flow through the lung was assessed as the difference between flow in the pulmonary artery and ductal flow; combined ventricular output as the sum of aortic and pulmonary artery flows; and flow through the foramen ovale as the difference between flows through the aorta and lungs.

Results-Blood flow through the lungs increased exponentially with gestational age $(r=0.89, p<0.001)$, by almost fourfold over the period of gestation studied, and was a mean (SD) of $22 \%(7 \%)$ of combined ventricular output. Blood flow through the foramen ovale increased exponentially by threefold $(r=0.77, p<$ 0.001 ), representing between $17 \%$ and $31 \%$ of combined ventricular output.

Conclusions-Blood flow through the lungs and across the foramen ovale can be calculated non-invasively in the normal human fetus. Both flows increase exponentially with age and comprise between one fifth and one quarter of the combined ventricular output, proportions that remain unchanged through the second and third trimesters of pregnancy.

(Br Heart F 1994;71:232-237)

During fetal growth and development, oxygenated blood returns to the right atrium from the placenta through the umbilical vein. It is preferentially streamed across the interatrial septum to the left side of the heart and distributed to the brachiocephalic circulation to support the disproportionately rapid cephalic growth that characterises the normal human fetus and other fetal primates. Most of our current understanding of blood flow through the fetal pathways has been derived from experimental animal models, in particular from the fetal lamb. ${ }^{1-4}$ These ovine studies have provided important insights into fetal circulatory dynamics, ${ }^{1-4}$ but lower order mammalian species differ in the distribution of blood flow particularly to the cephalic and placental circulations. ${ }^{5-9}$ As Doppler ultrasonography became available for routine human fetal monitoring, not only have cardiac structural abnormalities been diagnosed early in the second trimester, ${ }^{10-14}$ but a better understanding of cardiac pathophysiology has allowed an increasing number of therapeutic interventions to be undertaken before birth. ${ }^{15-19}$ Furthermore, the changes in right and left ventricular outputs during the last trimester of pregnancy have been estimated by several investigators and produced concordant results. ${ }^{20-23}$ Measurement of volume of blood flow by Doppler ultrasonography has been validated both in vitro with calibrated roller pumps ${ }^{24}$ and in vivo with electromagnetic flow probes in the ovine fetus. ${ }^{25}$ Little is known of blood flow through the lungs and less still about interatrial shunting of blood in the normal human fetus during growth. Direct assessment of flow through the foramen ovale is not possible as blood flow velocity across it is multiphasic ${ }^{26}$ and the cross sectional area of the foramen ovale cannot be assessed because of its irregular shape.

The aims of our study were to assess blood flow to the lungs and through the foramen ovale in the normal human fetus, to assess the changes in each with gestational age, and to determine the proportions of combined ventricular output they represent.

\section{Patients and methods}

PATIENT POPULATION

The study population consisted of 38 fetuses of mothers referred to the fetal cardiology department of Guy's Hospital who underwent Doppler sonography because they were considered to be at increased risk of fetal cardiac abnormalities either on account of previously 

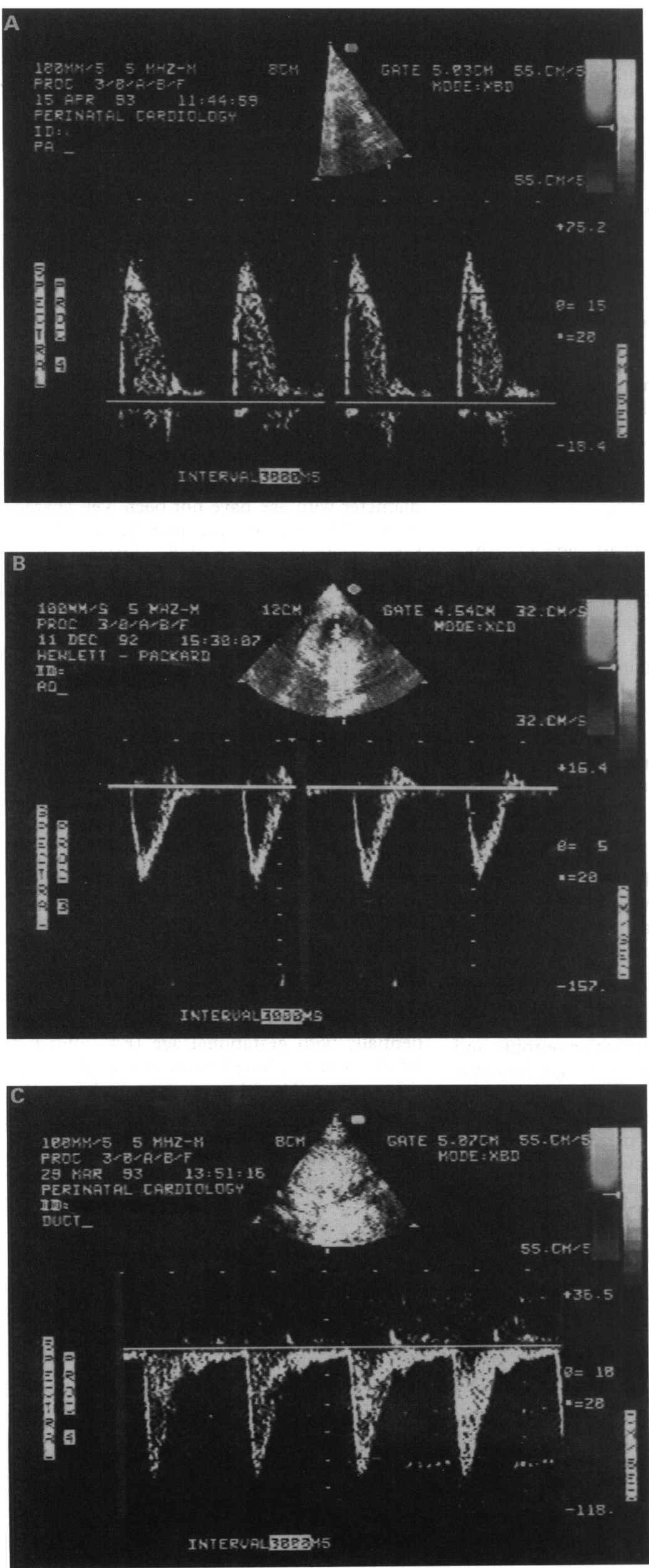

Figure 1 Doppler velocity signals obtained from $(A)$ main pulmonary artery, (B) ascending aorta, and (C) ductus arteriosus, in which there is characteristic greater systolic and smaller diastolic flow. abnormal pregnancies, immediate family histories of congenital heart disease, maternal diabetes, or exposure to a potential teratogen. Only fetuses with normal cardiac and circulatory anatomy and technically satisfactory Doppler echocardiograms were included. The mean (range) of gestational age was 26 (18-37) weeks.

ACQUISITION OF DATA

The maternal abdomen was scanned with a Hewlett Packard 77020A ultrasonoscope with a 3.5 or $5.0 \mathrm{MHz}$ transducer. The fetal heart was located and a systematic sequential chamber analysis performed to confirm normal atrial situs and concordant atrioventricular and ventriculoarterial connections. The gestational age of each fetus was assessed from the first day of the last menstrual period, and normal growth was corroborated by measurements of the biparietal cephalic diameter, femoral length, or both. Cross sectional echocardiographic images were recorded to measure arterial diameters of the proximal main pulmonary artery, the proximal ascending aorta, and the ductus arteriosus from its origin at the main pulmonary artery. Echocardiographic images of the three great arteries were acquired with the ultrasound beam as close to a right angle to the arterial walls as possible. Velocity signals of blood flow were obtained with pulsed wave Doppler from the three great arteries (fig 1). The Doppler sample volume was positioned within the lumen of each vessel. The pulsed wave Doppler beam was aligned as parallel as possible to the direction of blood flow. The angle of incidence between the Doppler insonating beam and the direction of blood flow in the great arteries was measured with the flow direction cursor, and recordings only analysed when this angle was $<20^{\circ}$ and no angle correction was applied. We chose $20^{\circ}$ because this underestimates true velocity by no more than $8 \%$.

\section{ANALYSIS OF DATA}

The diameters of the ascending aorta and main pulmonary arteries were measured above the levels of the semilunar valves and the diameter of the ductus arteriosus was measured distal to its origin. The measurement of the diameter of each great artery was made from at least three cardiac cycles from leading edge to leading edge with the electronic calipers and the software analysis package of the Hewlett Packard ultrasonoscope. Individual measurements of diameters of the great vessel were rounded off to the nearest $0.5 \mathrm{~mm}$ because of the limitations in axial resolution of the 3.5 and $5.0 \mathrm{MHz}$ transducer, and mean values were calculated for each artery. The cross sectional areas of the three great arteries were calculated assuming circular cross sections.

The Doppler velocity signals with the maximum amplitudes recorded from the ascending aorta, the main pulmonary artery, and the ductus arteriosus were digitised through the middle of the spectral envelopes with the Hewlett Packard microprocessor to obtain 
flow velocity time integrals for each vessel. A minimum of three Doppler velocity signals were digitised from each great artery and mean flow velocity integrals were calculated for each vessel. Mean heart rate was calculated in each fetus from the time intervals between consecutive Doppler velocity spectral envelopes of three cardiac cycles.

Volumes of blood flow in $\mathrm{ml} / \mathrm{min}(\mathrm{Q})$ in each of the great arteries were estimated as the product of heart rate (HR), flow velocity integral (FVI), and the cross sectional area (CSA) of the vessel:

$$
\mathrm{Q}=\mathrm{HR} \times \mathrm{FVI} \times \mathrm{CSA}
$$

Blood flow through the lungs (QL) was calculated as the difference between main pulmonary artery flow (QPA) and ductal flow (QD):

$$
\begin{aligned}
\mathrm{QL}= & \mathrm{QPA}-\mathrm{QD} \\
= & (\mathrm{HR} \times \mathrm{FVI} \times \mathrm{CSA})^{\mathrm{PA}}- \\
& (\mathrm{HR} \times \mathrm{FVI} \times \mathrm{CSA})^{\mathrm{D}}
\end{aligned}
$$

where $\mathrm{PA}=$ pulmonary artery, and $\mathrm{D}=$ ductus arteriosus.

Blood flow across the interatrial septum through the foramen ovale (QF) was estimated as the difference between $\mathrm{QL}$ and blood flow in the ascending aortic (QA):

$$
\begin{aligned}
\mathrm{QF} & =\mathrm{QA}-\mathrm{QL} \\
& =(\mathrm{HR} \times \mathrm{FVI} \times \mathrm{CSA})^{\mathrm{A}}-\mathrm{QL}
\end{aligned}
$$

where $\mathrm{A}=$ ascending aorta.

Combined ventricular output (CVO) was obtained as:

$$
\mathrm{CVO}=\mathrm{QA}+\mathrm{QPA}
$$

The proportions of combined ventricular output that lung blood flow and foramen ovale flow represented were calculated as the ratios $\mathrm{QL} / \mathrm{CVO}$ and QF/CVO respectively.

\section{STATISTICAL ANALYSIS}

The relation between ductal flow and gestational age, combined ventricular outputs and gestational age, blood flow through the lungs and gestational age, and between blood flow through the foramen ovale and gestational age were assessed by regression analysis. Gestational age was selected as the independent variable and the three estimations of blood flow were tested both as linear and logarithmic functions. The individual correlations were obtained (Pearson's correlation coefficients), and two sided $\mathrm{p}$ values and $95 \%$ confidence intervals ( $95 \% \mathrm{CIs)}$ for the predicted means were derived with an asymptotic $t$ statistic. Also, the variability of the ratios $\mathrm{QL} / \mathrm{CVO}$ and $\mathrm{QF} / \mathrm{CVO}$ with gestational age was evaluated.

The reproducibility of the echocardiographic measurements of the diameters of the great arteries and their impact on volume of flow has been previously reported ${ }^{921}$ and in our study was assessed in the three great vessels of 10 fetuses by two observers.

\section{Results}

The linear growth of the ascending aorta and

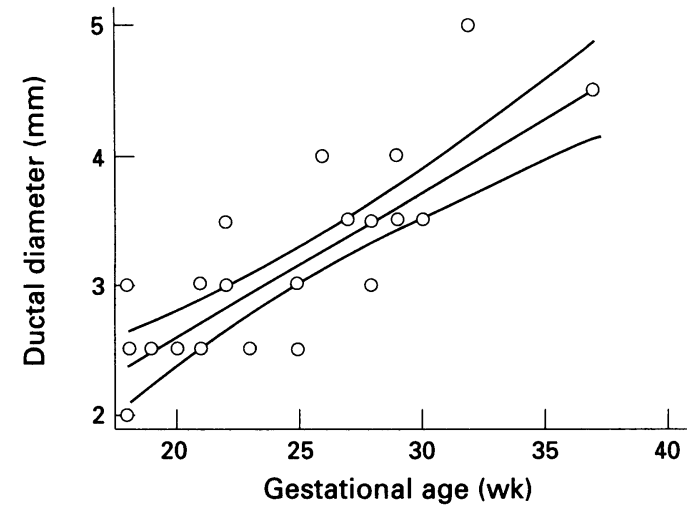

Figure 2 Relation between diameter of the ductus arteriosus and gestational age with 95\% CIs.

main pulmonary artery has been described previously, ${ }^{20-2327}$ but the changes in ductal diameter with age have not been well characterised. In our study, the diameter of the ductus arteriosus increased linearly with gestational age $(r=0.78 ; \mathrm{p}<0.001$; fig 2$)$. Peak blood flow velocities in the ascending aorta were higher than peak velocities recorded in the main pulmonary artery; both increased in amplitude with age. In fetuses between 18 and 22 weeks' gestation, blood flow velocities recorded in the ductus arteriosus were similar to those obtained in the main pulmonary artery. By contrast, in the fetuses $>22$ weeks' gestation, the peak velocity in the ductus arteriosus was substantially greater than the peak velocity in the main pulmonary artery, and when the pulsed wave Doppler sample volume was advanced from the main pulmonary artery into the ductus arteriosus there was an abrupt rise in amplitude of the peak blood flow velocity.

Combined ventricular output, assessed as the sum of the flows through the pulmonary artery and ascending aorta, increased exponentially with gestational age $(r=0.93 ; \mathrm{p}<$ $0.001)$ and is plotted therefore as the logarithm $v$ age. This shows a linear relation (fig 3). Mean of pulmonary arterial blood volume flow was about $10 \%$ greater than mean ascending aortic flow. Blood flow in the ductus arteriosus increased exponentially with age

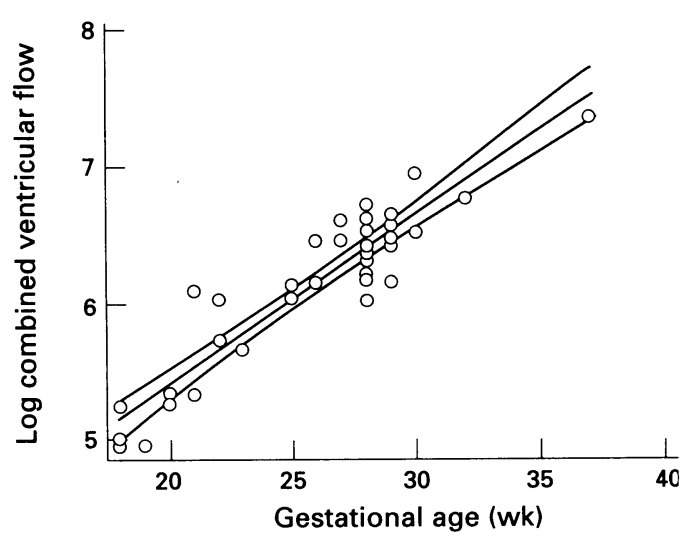

Figure 3 Relation between logarithm (In) of combined ventricular flow and gestational age with $95 \%$ CIs. 


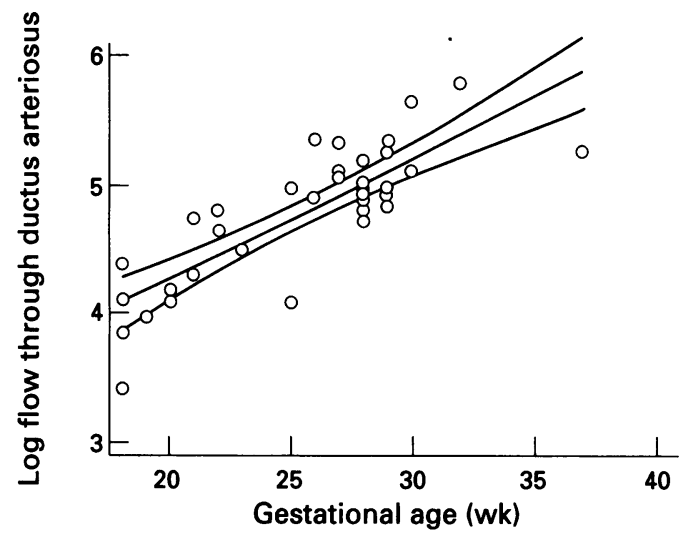

Figure 4 Relation between logarithm (In) of flow in the ductus arteriosus and gestational age with $95 \%$ CIs.

$(r=0.82 ; \mathrm{p}<0.001)$ and plotted as its logarithm showed a linear relation with gestational age (fig 4). This represented a mean of $47 \%$ of main pulmonary artery blood flow, a proportion that remained unchanged throughout the period of gestation studied.

Blood flow through the lungs, estimated as the difference between main pulmonary artery flow and ductal blood flow, increased exponentially $(r=0.89 ; \mathrm{p}<0.001)$ almost fourfold from 20 to 35 weeks and is shown as its logarithm $v$ age in fig 5 . Blood flow through the lungs comprised a mean (SD) of $22 \%$ (7\%) of combined ventricular output, a proportion that did not alter significantly with gestational age.

Volume of blood flow across the foramen ovale was determined indirectly as the difference between the blood volume returning from the lungs and blood volume in the ascending aorta. Flow through the foramen ovale increased exponentially $(r=0.77 ; \mathrm{p}<$ 0.001 ) almost threefold from 20 to 35 weeks of gestation and a plot of its logarithm $v$ age is linear (fig 6). Flow through the foramen ovale represented between $17 \%$ and $31 \%$ (mean $22 \%$ ) of combined ventricular output, a similar proportion to blood flow through the lungs and like the flow through the lungs varied little

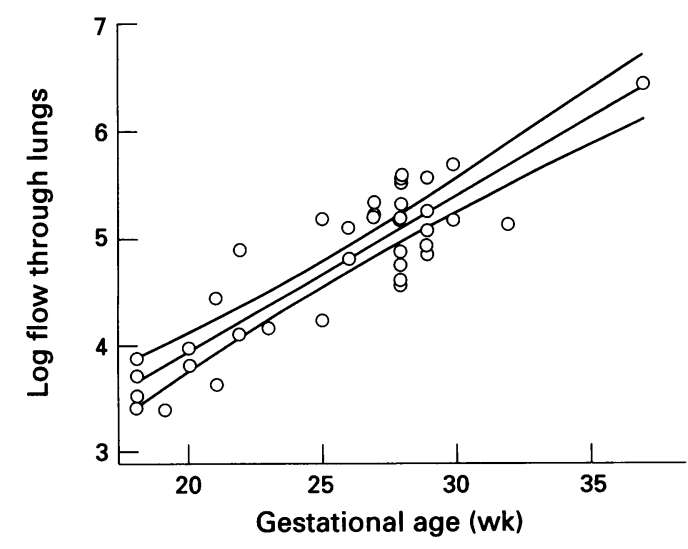

Figure 5 Relation between logarithm (n) of flow through the lungs and gestational age with $95 \%$ CIs.

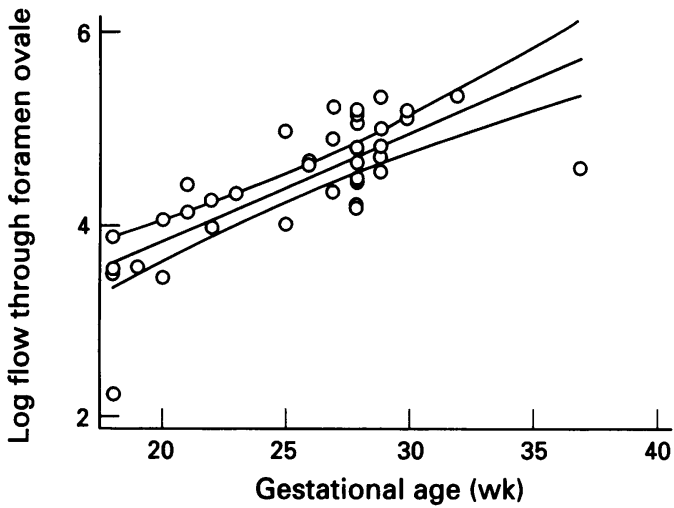

Figure 6 Relation between logarithm (In) of flow through the foramen ovale and gestational age with $95 \%$ CIs.

with gestational age. The reproducibility of echocardiographic measurements of arterial diameters was evaluated by two observers in 10 fetuses by regression analysis. The regression equation $(y=0.987 x+0.16)$ showed a correlation coefficient between observers of $r=0.94$ and an SEM of the estimate of $0.042 \mathrm{~cm}$.

\section{Discussion}

Ultrasound was initially introduced into maternal-fetal medicine for fetal screening in early detection of structural anomalies and for clinical monitoring of fetal wellbeing. Over the past decade, improvement in image resolution and the application of pulsed wave and colour flow Doppler have enabled intracardiac anatomy and haemodynamics to be unequivocally defined. These non-invasive tools have facilitated intrauterine diagnosis of congestive heart failure and complex structural heart disease from early in the second trimester. This has allowed clinically important therapeutic interventions to be planned electively during pregnancy, including fetal blood sampling and intravascular transfusions $^{18}$, antiarrhythmic treatment, ${ }^{15-17}$ balloon dilatation of valves, ${ }^{19}$ and corrective cardiac surgery to be performed early after parturition. The combination of high resolution imaging and Doppler has provided a method of measuring volume of blood flow in the heart and great vessels as the product of the Doppler flow velocity-time integral and the cross sectional area of the flow stream. Assessment of blood flow with this method has been validated in vivo in the ovine fetus with electromagnetic flow probes ${ }^{24}$ and in vitro against calibrated roller pumps. ${ }^{25}$ Cardiac output and placental blood flow have been assessed in the normal human fetus by a number of investigators and produced consistent results. ${ }^{20-23} \mathrm{By}$ contrast, little is known about blood flow through the ductus arteriosus during pregnancy, except that it may be importantly altered by indomethacin, ${ }^{28}$ which is used in the treatment of polyhydramnios. Hitherto, there has been no systematic attempt to measure blood flow through the lungs or through the foramen ovale in the 
normal human fetus or to investigate the changes in each with gestational age.

We assessed the volume of blood flow in the three arteries of 38 normal human fetuses as the products of heart rate, flow velocity integrals, and cross sectional areas, having assumed that arterial cross sections were circular. Pulmonary artery flow was consistently larger than ascending aortic flow as in previous reports. ${ }^{20-23}$ In fetuses of $<22$ weeks' gestation, peak blood flow velocity in the ductus arteriosus was similar to that in the main pulmonary artery, whereas peak blood flow velocity was substantially greater in the ductus of fetuses of $>22$ weeks' gestation. Moreover, in the older fetuses there was a rise in peak blood flow velocity when the Doppler sample volume was advanced from the main pulmonary artery into the ductus arteriosus, suggesting that the ductus was partially restrictive. The volume of blood flow each minute through the ductus increased progressively and exponentially with gestational age, and made up about $50 \%$ of pulmonary artery flow throughout the period of gestation studied, so that the functional significance of the step up in velocity of blood flow within the ductus could not be explained. The blood flow through the lungs was assessed as the difference between pulmonary artery and ductal flows, and increased exponentially more than threefold from 18 to 35 weeks' gestation in the normal fetuses we studied. The wide variability in blood flow to the lungs in the latter half of the second and during the last trimester most likely reflect genetically determined differences in fetal body weight and habitus that begin to be expressed during this period of gestation. Blood flow through the lungs represented about one fifth of combined ventricular output, and this proportion did not change with gestational age. The proportion of combined ventricular output that blood flow through the lungs represented in the human fetus was double that reported in the fetal lamb, ${ }^{134}$ and most likely reflects differences in regional blood flow between the two species. Furthermore, this relatively large proportion of cardiac output distributed to the lungs is consistent with the sizes of the branch pulmonary arteries and the pulmonary veins that appear full and not collapsed.

Blood flows across the interatrial septum through the widely patent foramen ovale to supply the brachiocephalic circulation with oxygenated blood and support the rapid cephalic growth that characterises normal human fetal growth. Volume of blood flow across the foramen ovale cannot be assessed directly because the blood flow velocity profile is multiphasic during the cardiac cycle ${ }^{26}$ and because the foramen ovale has an irregular shape that precludes accurate assessment of its cross sectional area. We assessed blood flow across the foramen ovale indirectly by subtracting blood flow through the lungs from that through the ascending aorta as this difference can only result from shunting of blood across the interatrial septum from right to left through the foramen ovale. A limitation of this method of measuring blood flow across the interatrial septum is that it takes no account of coronary or bronchial arterial flow, but both are small and moreover tend to cancel each other out. Blood flow through the foramen ovale increased more than threefold between 20 and 35 weeks' gestation and contributed more than half of the total left ventricular output, a proportion that did not alter significantly through the later part of the second and the third trimesters. Whether blood flow through the foramen ovale comprises even more of the combined ventricular output earlier in pregnancy when cephalic growth represents a comparatively greater proportion of the total body mass is unknown because accurate measurements of diameters of the great vessel during early fetal development is beyond the resolution of currently available ultrasound equipment.

We conclude that ductal flow and blood flow through the lungs and across the foramen all increase exponentially with age about threefold between 20 and 35 weeks' gestation. Blood flow through the lungs and foramen ovale comprise between one fifth and one quarter of the combined ventricular output, proportions that do not change significantly during the second and third trimesters of normal pregnancy. These initial data on blood flow through the lungs and the foramen ovale in the normal human fetus and their respective changes with gestational age are numerically and proportionally substantially different from the corresponding data reported in experimental animals. Now that Doppler ultrasound can be safely used to monitor the human fetus, the distribution of the combined ventricular output can be determined in the normal fetus in its undisturbed, normal state.

1 Dawes GS. The fetal circulation. In: Dawes GS ed. Fetal and Neonatal Physiology. Chicago: Year Book Medical Publishers, 1968, 91-114.

2 Rudolph AM, Heymann MA. Circulatory changes during growth in the fetal lamb. Cir Res 1970;26:289-99.

3 Heymann MA, Creasy RK, Rudolph AM. Quantitation of blood flow patterns in the fetal lamb in utero. In: Comline KS, Cross KW, Dawes GS, Nathanielsz In: Comline KS, Cross KW, Dawes GS, Nathanielsz
PW, eds. Fetal and Neonatal Physiology. Cambridge: PW, eds. Fetal and Neonatal Physiology.

4 Rudolph AM. Distribution and regulation of blood flow in the fetal and neonatal lamb. Circ Res 1985;57:811-20.

5 St John Sutton M, Gill T, Plappert T. Quantitation of brachio-cephalic blood flow in the normal human fetus [abstract]. Eur Heart $\mathcal{F}$ 1990;11:90

6 Gill RW, Trudinger BJ, Garrett WJ, Kossof G, Warren PS. Fetal umbilical venous flow measured in utero by pulsed Doppler and B-mode ultrasound. I. Normal pregnancies. Am f Obstet Gynecol 1981;139:720-5.

7 Kurjak A, Raihvain B. Ultrasonic measurements of umbilical blood flow in normal and complicated pregnancies. f Perinat Med 1982;10:3-16.

8 Al-Ghazali W, Chapman MG, Allan LD. Doppler assessment of the cardiac and uteroplacental circulations in normal and abnormal fetuses. $\mathrm{Br} \mathcal{F}$ Obstet Gynaecol 1988;95:575-80.

9 St John Sutton M, Theard MA, Bhatia SJS, Plappert T, Saltzman DH, Doubilet P. Changes in placental blood flow in the normal human fetus with gestational age. Pediatr Res 1990;28:383-7.

10 Allan LD, Tynan MJ, Campbell S, Anderson RH. Identification of cardiac malformations by echocardiography

11 Allan LD, Crawford DC, Anderson RH, Tynan MJ Echocardiographic and anatomical correlations in fetal Echocardiographic and anatomical correlations in

congenital heart disease. Br Heart $\mathcal{F}$ 1984;52:542-8.
12 Allan LD, Crawford DC, Chita SK, Tynan MJ. Prenatal sllan LD, Crawford DC, Chita SK, Tynan MJ. Prenatal
screening for congenital heart disease. BMF 1986;292: screening 
13 Crawford DC, Chita SK, Allan LD. Prenatal detection of congenital heart disease: factors affecting obstetric management

14 Sharland GK, Lockhart SM, Chita SK, Allan LD. Factors influencing the outcome of congenital heart disease detected prenatally. Arch Dis Child 1990;65:284-7.

15 Kleinman CS, Copel JA, Weinstein EM, Santulli TV, Hobbins JC. Treatment of fetal supraventricular tachyarrhythmias. $¥ C U$ 1985;13:265-73.

16 Maxwell DJ, Crawford DC, Curry PVM, Tynan MJ, Allan LD. Obstetric importance, diagnosis, and management of fetal tachycardias. BMf 1988;297:107-10

17 Allan LD, Chita SK, Sharland GK, Maxwell D, Priestley $\mathrm{K}$. Flecainide in the treatment of fetal tachycardias. $\mathrm{Br}$ Heart $\mathcal{F} 1991 ; 65: 46-8$.

18 Daffos F, Capella-Pavlovsky M, Forestier F. Fetal blood sampling during pregnancy with needle guided by ultrasound. A study of 606 consecutive cases. Am $\mathcal{F}$ Obstet Gynecol 1985;153:655-9.

19 Maxwell DJ, Allan LD, Tynan MJ. Balloon aortic valvuloplasty in the fetus: a report of two cases. $\mathrm{Br}$ Heart $\mathrm{f}$ 1991;65:256-8.

20 Reed KI, Meijboom EJ, Sahn DJ, Scagnelli SA, ValdesCruz LM, Shenker L. Cardiac Doppler flow velocities in human fetuses. Circulation 1986;73:41-6.

21 Kenny J, Plappert T, Doubilet P, Saltzman DH, Cartier $M$, Zollars $\mathrm{L}$, et al. Changes in intracardiac blood flow velocities and right and left ventricular stroke volumes with gestational age in the normal human fetus: a prospective Doppler echocardiographic study. Circulation 1986;74:1208-16.

22 De Smedt MCH, Cisser GHA, Meijboom EJ. Fetal cardiac output estimated by Doppler echocardiography during mid and late gestations. Am $\mathcal{f}$ Cardiol 1987; 60:338-42.

23 Allan LD, Chita SK, Al-Ghazali W, Crawford DC, Tynan MJ. Doppler echocardiographic evaluation of the normal human fetal heart. Br Heart 7 1987;57:528-33.

24 Schmidt KG, Di Tommaso M, Silverman NH, Rudolph AM. Doppler echocardiographic assessment of fetal descending aortic and umbilical blood flows. Validation study in fetal lambs. Circulation 1991;83:1731-7.

25 Stewart WJ, Jiang L, Mich R, Pandian N, Guerrero JL, Weyman AE. Variable effects of changes in flow rate Weyman AE. Variable effects of changes in flow rate
through the aortic, pulmonary and mitral valves on valve areas and flow velocity; impact on quantitative Doppler flow calculations. ₹ Am Coll Cardiol 1985;6:653-61.

26 Soyeur D, Schaaps J-P, Kulbertus H. Pulsed Doppler assessment of fetal blood flow across the foramen ovale and pulmonary vascular bed [abstract]. Eur Heart $\mathcal{f}$ 1990;11:90.

27 Cartier MS, Davidoff A, Warneke LA, Hirsh MP, Bannon $S$, St John Sutton M, Doubilet PM. The normal diameter of the fetal aorta and pulmonary artery: echocardioof the fetal aorta and pulmonary artery: echocardio-

graphic evaluation in utero. $A \mathcal{F} R$ 1987;149:1003-7.
28 Huhta JC, Moise KJ, Fisher DJ, Sharif DS, Wasserstrum $\mathrm{N}$, Martin C. Detection and quantitation ao constriction of the fetal ductus arteriosus by Doppler echocardiography. Circulation 1987;75:406-12. 